\title{
Concentration-Dependent Fluorescence Color Tuning of the Difluoroboron Avobenzone Complex in Polymer Films
}

\author{
Fuyuki Ito, ${ }^{* 1}$ and Chika Kikuchi ${ }^{1}$ \\ ${ }^{1}$ Institution of Education, Shinshu University, 6-ro, Nishinagano, Nagano city, 380-8544 \\ E-mail: <fito@shinshi-u.ac.jp>
}

\begin{abstract}
We have investigated concentration-dependent fluorescence color tuning of $\mathrm{BF}_{2} \mathrm{AVB}$ in a poly(methyl methacrylate) film. $\mathrm{BF}_{2} \mathrm{AVB}$ exhibits a color change from purple-blue to orange via green, and then crystals segregate from the polymer matrix. We analyzed the fluorescence and fluorescence excitation spectral change as a function of the $\mathrm{BF}_{2} \mathrm{AVB}$ concentration in the film. We also obtained fluorescence microscope images to confirm the miscibility and crystallization properties in the films. This originates from the aggregated state formed in the polymer matrix depending on the stacking structure of the parallel (B-phase), antiparallel (G-phase), and amorphous states. The emissive species change with increasing $\mathrm{BF}_{2} \mathrm{AVB}$ concentration. The polymer matrix isolation method enables not only directly visualization of the dynamics of the crystal formation process and Ostwald's rule of stages by fluorescence changes, but it also enables device fabrication, such as fabrication of organic light-emitting diodes and luminescent solar concentrators.
\end{abstract}

\section{Introduction}

Fluorescent polymer films have been widely studied: not only synthesized dye-labeled polymers ${ }^{1,2}$ but also fluorescent dyes dispersed in conventional optical polymers such as poly(methyl methacrylate) (PMMA) ${ }^{3-7}$ and poly(vinyl alcohol) (PVA). ${ }^{8-10}$ Luminescent solar concentrators (LSCs) are one of the applications of fluorescent dye dispersed polymer films because they require a high fluorescence quantum yield to efficiently collect and transport sunlight. ${ }^{11-14}$ In the case of dye-dispersed polymer films, molecular formations, e.g., monomers, aggregates, or microcrystals, in the thin films are also crucial for their performance, because the fluorescence band, quantum yield, and exciton diffusion are influenced by the intermolecular interactions of the dyes. Therefore, for controlling their dispersion state, it is important for there to be miscibility between the dyes molecules and the polymer. ${ }^{13}$ For example, the fluorescence quantum of many organic fluorescence dyes, such as laser dyes, decreases with increasing concentration and the solid state rarely shows emission, which is called "concentration quenching" because it causes formation of aggregates, such as $\mathrm{H}$ aggregates. Highly dye-doped polymer films also affect concentration quenching, which originates from aggregate formation by phase separation in the polymer films. It is important to understand and control the dispersion state of the dye molecules in the polymer matrix. ${ }^{15}$ Evaluation and optimization are crucial to prepare photofunctional polymer films based on the fluorescence properties of the dyes.

We have investigated the fluorescence properties of a pyrene ammonium derivative ${ }^{16}$ and a perylene ammonium derivative $^{17,18}$ in a PVA matrix and perylene in a PMMA matrix. At low dye concentrations in the polymer films, the films only showed monomer emission. The fluorescence peak red-shifted with increasing dye concentration, which was attributed to dimer or excimer-like emission. The fluorescence spectral changes originated from formation of aggregates by phase separation (segregation) in the films with increasing dye concentration. The concentration dependent hierarchal change was presumed to show a molecular assembly process, suggesting it can be detected by the fluorescence properties. We proposed that the concentration-dependent fluorescence spectral change is because of matrix isolation of crystal growth and/or freezing of their growth by the polymer chain. ${ }^{16}$ This indicates that the concentration-dependent fluorescence spectral change enables us to evaluate not only the molecular assemblies, crystal nucleus formation, and growth process of fluorescent organic molecules in the polymer matrix but also tuning of the fluorescence color in films with the same molecules. ${ }^{19}$ However, the molecular form in the polymer film cannot be specified according to the mutual state between the monomer and the crystal. A molecule that shows a fluorescence color change owing to molecular stacking or intermolecular interactions provides information about the changes of the molecular arrangement with the concentration.

Dibenzoylmethanatoboron difluoride $\left(\mathrm{BF}_{2} \mathrm{DBM}\right)$ derivatives have excellent optical properties, for example, two-photon absorption cross-sections, ${ }^{20,}{ }^{21}$ high fluorescence quantum yield in the solid state, ${ }^{22}$ multiple fluorescence colors, ${ }^{23-25,26,} 27$ and reversible mechanofluorochromic properties. ${ }^{28,}{ }^{29}$ In particular, $\mathrm{BF}_{2} \mathrm{DBM}$ based on the 4-tert-butyl-4'-methoxydibenzoylmethane (avobenzone) boron difluoride complex $\left(\mathrm{BF}_{2} \mathrm{AVB}\right)$ exhibits different emission depending on the crystal phase (polymorph) ${ }^{30} \mathrm{BF}_{2} \mathrm{AVB}$ also has excellent fatigue resistance by photoirradiation and a high fluorescence quantum yield even in the solid state $(\sim 0.5)$, which is advantageous for photonics applications. Tsuchiya et al. reported full-color-tunable organic light-emitting diodes (OLEDs) that can achieve white emission using a single emitter. ${ }^{31}$ Furthermore, they proposed a new strategy exploiting both aggregation and exciplex formation, which is called aggregation-induced exciplex formation. Aggregate formation induces an emission color shift from blue to green. A further color change to red occurs by aggregation-induced exciplex formation through triadic exciplex formation between aggregated $\mathrm{BF}_{2} \mathrm{AVB}$ and host molecules. These results suggest that the aggregated structure is crucial to achieve emission color tuning in devices. Therefore, we need to obtain detailed information about the fluorescence color of $\mathrm{BF}_{2} \mathrm{AVB}$ in films as a function of the $\mathrm{BF}_{2} \mathrm{AVB}$ concentration. 
<smiles>COc1ccc(C2=CC(c3ccc(C(C)(C)C)cc3)=C[B-](F)(F)O2)cc1</smiles>

Figure 1. Molecular structure of $\mathrm{BF}_{2} \mathrm{AVB}$.

In this study, we investigated the concentration-dependent fluorescence color tuning of $\mathrm{BF}_{2} \mathrm{AVB}$ in a PMMA film. First, we analyzed both the fluorescence and fluorescence excitation spectral changes as a function of the $\mathrm{BF}_{2} \mathrm{AVB}$ concentration in the polymer film. Next, we obtained fluorescence microscope images to confirm the miscibility and crystallization properties in the polymer films. The concentration-dependent fluorescence spectral changes also provide insight into the molecular assembly and crystal formation of the dye molecules.

\section{Experimental}

$\mathrm{BF}_{2} \mathrm{AVB}$ was synthesized according to a previous report. $^{23,29}$ Perylene was purified by repeated zone refining. PMMA with a number-average molecular weight of 350000 was purchased from Sigma-Aldrich (Schnelldorf, Germany) and it was used as-received. The $\mathrm{BF}_{2} \mathrm{AVB}$-doped PMMA thin films were prepared by drop-casting toluene solutions containing $2 \mathrm{wt} \%$ PMMA onto quartz plates. $\mathrm{BF}_{2} \mathrm{AVB}$ was added to the PMMA/toluene solutions at concentrations from 0.01-9.5 mol\% relative to the amount of PMMA monomer units. The cast films were dried under vacuum for $24 \mathrm{~h}$ at 298 K. UV-vis absorption spectra were acquired with a Shimadzu UV-2450 spectrometer, and fluorescence spectra were recorded on a Shimadzu RF-5300PC fluorescence spectrophotometer. The fluorescence color, morphology of the films, and crystal shape were captured with an inverted microscope (Olympus IX71) with high-pressure mercury lamp excitation and a dichroic mirror (Olympus WU filter cube). The microscope was combined with a charge-coupled device camera (Sigma Koki SK-TC202USB-AT) and a USB 4000 spectrometer (Oscan Optics). This instrument was not corrected for the wavelength dependence of the detectors. The microscope objective lens was a $40 \times$, N.A. 1.45 , oil immersion, plan apochromat (1-U2B616 Olympus). All of the experiments were carried out at room temperature.

\section{Results and Discussion}

Figure 2 shows the absorption spectra of $\mathrm{BF}_{2} \mathrm{AVB}$ in PMMA films with different $\mathrm{BF}_{2} \mathrm{AVB}$ concentrations. Absorption peaks are observed at 380 and $410 \mathrm{~nm}$. The band at $380 \mathrm{~nm}$ is assigned to the $\pi-\pi^{*}$ transition of the electron density delocalized over the whole molecule, as reported by Mirochnik et al. ${ }^{32,33}$ The absorbance is not proportional to the concentration of the dye, suggesting that there are intermolecular interactions between the $\mathrm{BF}_{2} \mathrm{AVB}$ molecules in polymer films. The absorption spectra are flat around the peak for $\mathrm{BF}_{2} \mathrm{AVB}$ concentrations up to $0.7 \mathrm{~mol} \%$. This most probably originates from stray light owing to self-emission from the $\mathrm{BF}_{2} \mathrm{AVB}$ film. These findings suggest that $\mathrm{BF}_{2} \mathrm{AVB}$ has a high fluorescence quantum yield even in a polymer film.

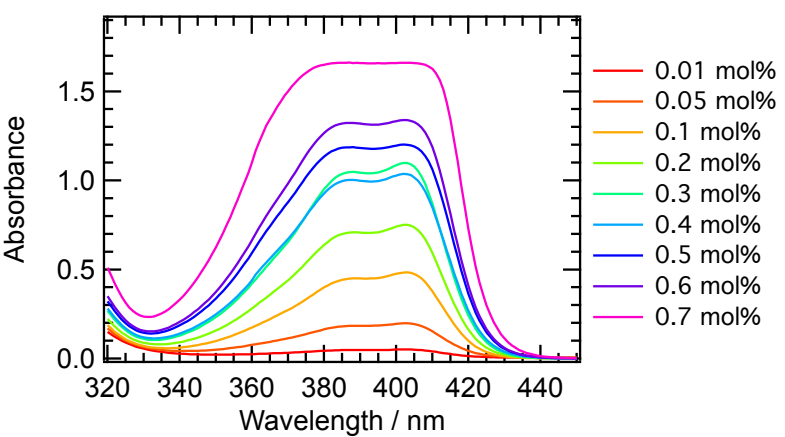

Figure 2. Absorption spectra of $\mathrm{BF}_{2} \mathrm{AVB}$ in PMMA films containing different $\mathrm{BF}_{2} \mathrm{AVB}$ concentrations.

Figure 3 shows the fluorescence spectra of $\mathrm{BF}_{2} \mathrm{AVB}$ in PMMA films containing different $\mathrm{BF}_{2} \mathrm{AVB}$ concentrations. The fluorescence spectra were normalized by the maximum intensity. At the lowest $\mathrm{BF}_{2} \mathrm{AVB}$ concentration of $0.01 \mathrm{~mol} \%$, a sharp fluorescence band is observed at $410 \mathrm{~nm}$ with a shoulder peak at $440 \mathrm{~nm}$. It originates from the fluorescence spectrum of monomeric $\mathrm{BF}_{2} \mathrm{AVB}$ in dilute solution. The fluorescence peaks red-shifted with increasing concentration along with increasing intensity of the tail. Although the fluorescence band is quenched in the shorter wavelength region, emission bands appear with increasing $\mathrm{BF}_{2} \mathrm{AVB}$ concentration in the longer wavelength region. New broad fluorescence bands are present at around 470 and $530 \mathrm{~nm}$ for $\mathrm{BF}_{2} \mathrm{AVB}$ concentrations of 1.4$3.0 \mathrm{~mol} \%$. The observed decrease of the monomer band with increasing $\mathrm{BF}_{2} \mathrm{AVB}$ concentration could be because of reabsorption or inner filter effects of the fluorescence or energy transfer to the broad fluorescence band located in the longer wavelength region. The fluorescence maximum shifts to 500 $\mathrm{nm}$ associated with full quenching of the fluorescence peak around $440 \mathrm{~nm}$ for $4.0 \mathrm{~mol} \% \mathrm{BF}_{2} \mathrm{AVB}$. Fraser et al. reported that there are several emissive states in the solid, crystalline, and amorphous states, which strongly depend on the packing and morphology (polymorphism) ${ }^{30}$ The green emissive species (G-phase) arises from the antiparallel dimer (tert-butyl groups on opposite sides) of $\mathrm{BF}_{2} \mathrm{AVBs}$, which was confirmed by X-ray crystallography. Conversely, the tert-butyl groups are clustered on the same side of the dimer (parallel dimer) in the blue emissive species (B-phase). The difference in the emissive properties of the dimers originates from the conjugation length owing to $\pi-\pi$ stacking and the planarity of $\mathrm{BF}_{2} \mathrm{AVB}$ in the dimer. The broad peak at $530 \mathrm{~nm}$ can be assigned to the amorphous state. The fluorescence properties are the same as those previously reported by Fraser et al. ${ }^{30}$

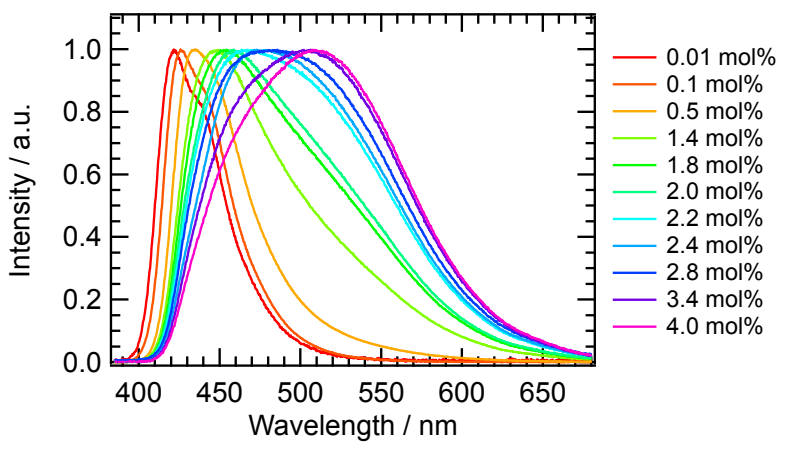

Figure 3. Fluorescence spectra of $\mathrm{BF}_{2} \mathrm{AVB}$ excited at 375 $\mathrm{nm}$ in films containing different $\mathrm{BF}_{2} \mathrm{AVB}$ concentrations.

Figure 4 shows the fluorescence excitation spectra of 
$\mathrm{BF}_{2} \mathrm{AVB}$ in PMMA films containing different $\mathrm{BF}_{2} \mathrm{AVB}$ concentrations monitored at 420 and $470 \mathrm{~nm}$. For the monitoring wavelength of $420 \mathrm{~nm}$, peaks are observed at 380 and $405 \mathrm{~nm}$ for all of the $\mathrm{BF}_{2} \mathrm{AVB}$ concentrations, and these are the same as the absorption bands of $\mathrm{BF}_{2} \mathrm{AVB}$, as shown in Figure 2. This finding indicates that the emission band of 420 $\mathrm{nm}$ originates from the monomer fluorescence of $\mathrm{BF}_{2} \mathrm{AVB}$. In contrast, the excitation spectra monitored at $495 \mathrm{~nm}$ are strongly dependent on the $\mathrm{BF}_{2} \mathrm{AVB}$ concentration. Peaks are observed at 380 and $405 \mathrm{~nm}$ below $0.1 \mathrm{~mol} \% \mathrm{BF}_{2} \mathrm{AVB}$, similar to the excitation spectra monitored at $420 \mathrm{~nm}$, which originate from the fluorescence of the $\mathrm{BF}_{2} \mathrm{AVB}$ monomer. The bands split with increasing $\mathrm{BF}_{2} \mathrm{AVB}$ concentration: the peak at 380 $\mathrm{nm}$ shifts to shorter wavelength and the peak at $405 \mathrm{~nm}$ shifts to longer wavelength. This suggests that intermolecular interactions exist in the ground state; that is, the molecules form aggregates or crystals.
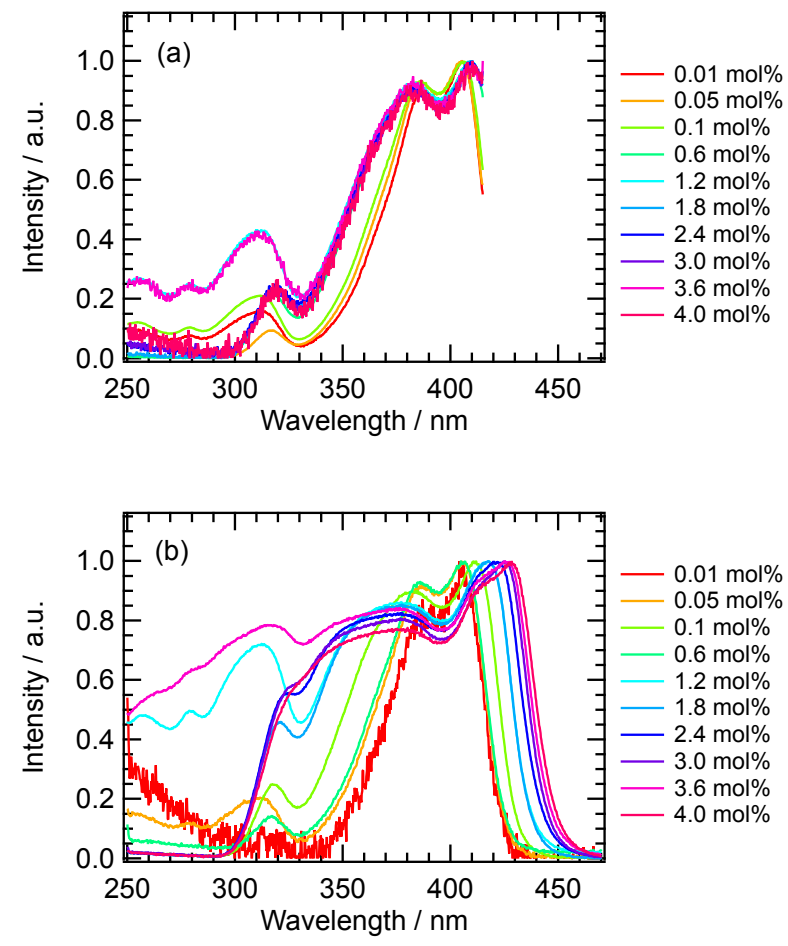

Figure 4. Fluorescence excitation spectra of $\mathrm{BF}_{2} \mathrm{AVB}$ for films containing different $\mathrm{BF}_{2} \mathrm{AVB}$ concentrations monitored at (a) 420 and (b) $495 \mathrm{~nm}$.

The splitting of the absorption bands because of intermolecular interactions is known as Kasha's exciton interaction. ${ }^{34}$ The transition energy and number of molecules in one-dimensional aggregates based on the exciton interaction are related by the following equation: ${ }^{35}$

$$
E_{N}=E_{1}-((N-1) / N)\left(E_{1}-E_{\infty}\right)
$$

where $E_{N}$ is the transition energy of the aggregation number $N$, $E_{1}$ is the transition energy of an isolated molecule, and $E_{\infty}$ is the transition energy of an infinite chain. We estimated the aggregation number of molecules in the PMMA films. From the excitation spectrum of the PMMA film with $0.01 \mathrm{~mol} \%$ $\mathrm{BF}_{2} \mathrm{AVB}$ monitored at $495 \mathrm{~nm}, E_{1}=1100 \mathrm{~cm}^{-1}$. The value of $E_{\infty}$ is $3300 \mathrm{~cm}^{-1}$, which is the convergent value of the peak shift at $4.0 \mathrm{~mol} \% \mathrm{BF}_{2} \mathrm{AVB}$. The calculated results are plotted as a function of the $\mathrm{BF}_{2} \mathrm{AVB}$ concentration in Figure 5. The $N$ value is relatively low below $2.5 \mathrm{~mol} \% \mathrm{BF}_{2} \mathrm{AVB}$ and then the aggregate size dramatically increases above $3.0 \mathrm{~mol} \% \mathrm{BF}_{2} \mathrm{AVB}$. The exciton splitting of the fluorescence excitation bands of $\mathrm{BF}_{2} \mathrm{AVB}$ suggests $\mathrm{H}$ - and J-aggregates formation with increasing $\mathrm{BF}_{2} \mathrm{AVB}$ concentration (Davydov splitting). Based on the band splitting calculated with Eq. (1), the average numbers of molecules in the aggregates were estimated to be 2 and 14 for 1.8 and $4.0 \mathrm{~mol}^{2} \mathrm{BF}_{2} \mathrm{AVB}$, respectively. These values are the same as those reported in a previous study of $\mathrm{BF}_{2} \mathrm{DBM}$ in PMMA films. ${ }^{36}$

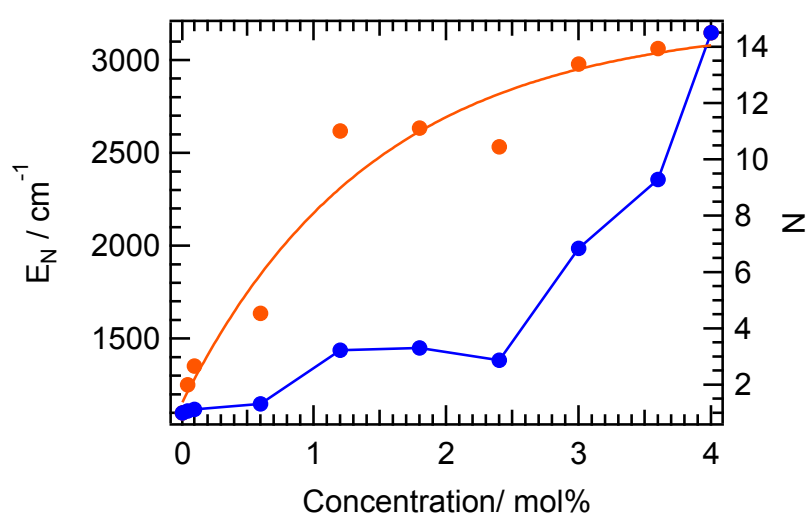

Figure 5. Fluorescence peak shift (orange) and estimated number of $\mathrm{BF}_{2} \mathrm{AVB}$ molecules in each aggregate (blue) in PMMA films as a function of $\mathrm{BF}_{2} \mathrm{AVB}$ concentration.

The fluorescence spectra were analyzed by nonlinear least squares fitting with five Gaussians. The peak positions and widths are listed in Table 1. All of the spectra were reproduced well with these values. The positions of peaks 1 and 2 correspond to the monomer fluorescence band, those of peaks 3 and 4 correspond to the excimers of the blue type (B-phase) and green type (G-phase), and that of peak 5 corresponds to the amorphous emission. ${ }^{30}$ The relative fractions of the monomer (peaks 1 and 2), B-phase excimer (peak 3), G-phase excimer (peak 4), and amorphous (peak 5) states as a function of the $\mathrm{BF}_{2} \mathrm{AVB}$ concentration are shown in Figure 6. The monomer fraction monotonically decreases with increasing $\mathrm{BF}_{2} \mathrm{AVB}$ concentration. The B-phase fraction slightly increases with increasing $\mathrm{BF}_{2} \mathrm{AVB}$ concentration below $0.5 \mathrm{~mol} \% \mathrm{BF}_{2} \mathrm{AVB}$ and then gradually decreases. The G-phase is not present at concentrations less than $0.5 \mathrm{~mol} \%$. The G-phase fraction then gradually increases with increasing $\mathrm{BF}_{2} \mathrm{AVB}$ concentration above $0.5 \mathrm{~mol} \%$ with a concomitant decrease in the fraction of the B-phase. The fraction of the amorphous phase gradually increases with increasing $\mathrm{BF}_{2} \mathrm{AVB}$ concentration up to 1.5 $\mathrm{mol} \%$. The emissive species in the film with $4.0 \mathrm{~mol} \%$ $\mathrm{BF}_{2} \mathrm{AVB}$ are mainly the G-phase and the amorphous phase with a small amount of the B-phase.

Table 1. Positions and widths of the Gaussians peaks used to

simulate the fluorescence spectral changes of $\mathrm{BF}_{2} \mathrm{AVB}$.

\begin{tabular}{cccccc}
\hline & Peak & Peak & Peak & Peak & Peak \\
& 1 & 2 & 3 & 4 & 5 \\
\hline $\begin{array}{c}\text { Position } \\
/ \mathrm{cm}^{-1}\end{array}$ & 23900 & 23040 & 22000 & 20165 & 18230 \\
$(/ \mathrm{nm})$ & 418 & 434 & 454 & 495 & 548 \\
$\begin{array}{c}\text { Width } / \\
\mathrm{cm}^{-1}\end{array}$ & 652 & 767 & 1288 & 2438 & 1732 \\
\hline
\end{tabular}




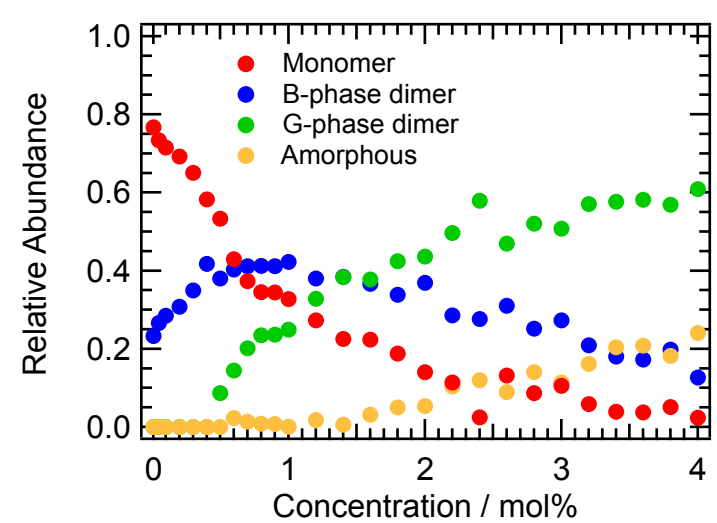

Figure 6. Changes of the relative abundance of the $\mathrm{BF}_{2} \mathrm{AVB}$ species from fitting of the fluorescence spectra based on five Gaussian peaks as a function of the $\mathrm{BF}_{2} \mathrm{AVB}$ concentration. The concentration range is below that for segregation of $\mathrm{BF}_{2} \mathrm{AVB}$ crystals.

Based on the above results, the concentration-dependent fluorescence spectrum change of $\mathrm{BF}_{2} \mathrm{AVB}$ in PMMA films before segregation is summarized in Figure 7. The fluorescence spectrum of the $0.01 \mathrm{~mol} \% \mathrm{BF}_{2} \mathrm{AVB}$ film is mainly attributed to the monomer, and there is $20 \%$ of the B-phase dimer. This probably originates from the larger equilibrium constant of monomer-dimer aggregation. With increasing $\mathrm{BF}_{2} \mathrm{AVB}$ concentration, the fraction of the monomer decreases with concomitant increase of first the fraction of the B-phase dimer and then the G-phase dimer. The fraction of the amorphous phase increases for $\mathrm{BF}_{2} \mathrm{AVB}$ concentrations greater than 1.5 $\mathrm{mol} \%$ associated with a decrease of the fraction of the B-phase. The thermodynamic stability of the G-phase is higher than that of the $\mathrm{B}$-phase, because the green crystal of $\mathrm{BF}_{2} \mathrm{AVB}$ is more stable than the cyan crystal. In OLED devices, the B-phase acts as a blue emissive species and the G-phase acts as a green emissive species. $^{31}$

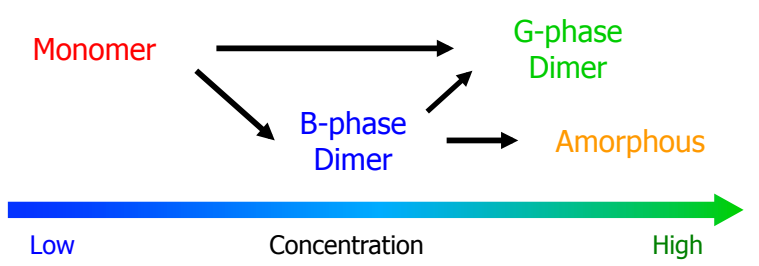

Figure 7. Change of the $\mathrm{BF}_{2} \mathrm{AVB}$ species based on fitting the fluorescence spectrum by five Gaussian peaks as a function of the $\mathrm{BF}_{2} \mathrm{AVB}$ concentration. The concentration range is below that for segregation of $\mathrm{BF}_{2} \mathrm{AVB}$ crystals.

To further investigate the concentration dependence of the fluorescence, we measured the fluorescence color and fluorescence images of the films. Figure 8 shows fluorescence microscope images of $\mathrm{BF}_{2} \mathrm{AVB}$ for PMMA films containing different $\mathrm{BF}_{2} \mathrm{AVB}$ concentrations. The fluorescence color is blue for $0.05-1.0 \mathrm{~mol} \% \mathrm{BF}_{2} \mathrm{AVB}$. The fluorescence color changes from blue to green above $1.2 \mathrm{~mol} \% \mathrm{BF}_{2} \mathrm{AVB}$, which is similar to the fluorescence spectra of the films. The fluorescence color then changes to greenish orange with increasing $\mathrm{BF}_{2} \mathrm{AVB}$ concentration until $4.0 \mathrm{~mol} \%$. Spherical crystal aggregates with blue-green emission are observed up to $5.0 \mathrm{~mol} \% \mathrm{BF}_{2} \mathrm{AVB}$, which is ascribed to segregation of $\mathrm{BF}_{2} \mathrm{AVB}$ from the PMMA matrix. Above $7.5 \mathrm{~mol} \% \mathrm{BF}_{2} \mathrm{AVB}$, clear needle-like crystals with blue-green emission are observed in the films, which are similar to the prism-like crystals reported by Fraser et al. ${ }^{23}$ This finding indicates that $\mathrm{BF}_{2} \mathrm{AVB}$ can uniformly disperse below $4.0 \mathrm{~mol} \% \mathrm{BF}_{2} \mathrm{AVB}$. Based on the finding that the polymer isolates the molecules in the films, the fluorescence changes could be the same as the molecular assembling process reached at crystal nucleus formation. ${ }^{36,37}$ The appearance of each species agrees with their thermal stability, suggesting that the concentration-dependent fluorescence change enabled us to visualize Ostwald's rule of stages.

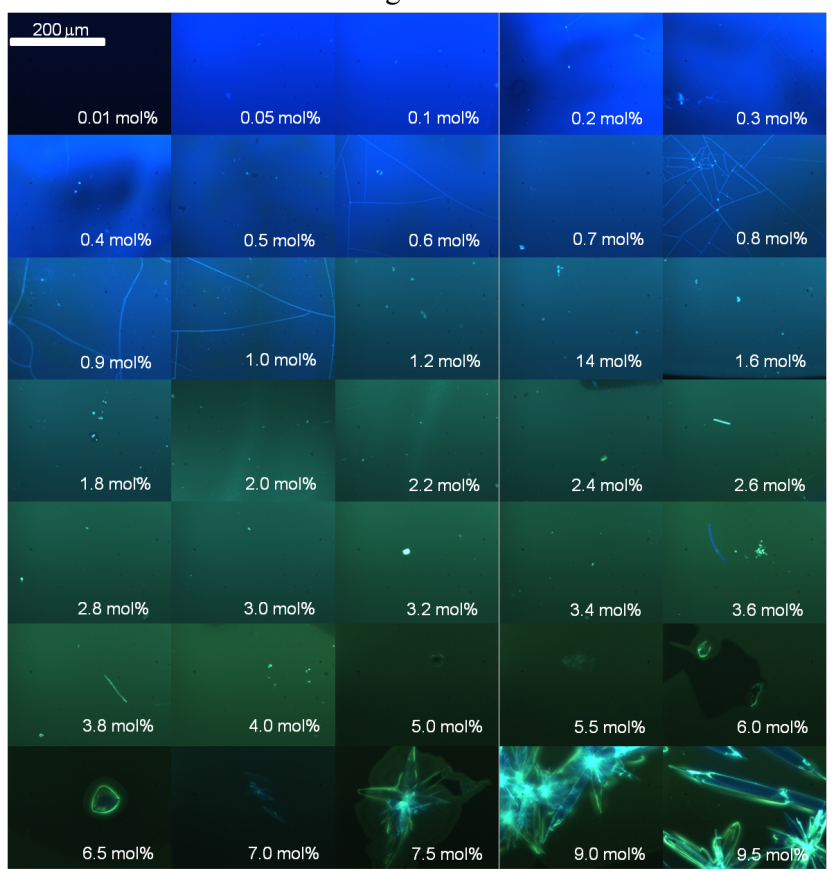

Figure 8. Fluorescence microscope images of PMMA films containing different $\mathrm{BF}_{2} \mathrm{AVB}$ concentrations.

\section{Conclusion}

We have achieved fluorescence color tuning of $\mathrm{BF}_{2} \mathrm{AVB}$ by changing the $\mathrm{BF}_{2} \mathrm{AVB}$ concentration in PMMA films. The color changes from blue to greenish-yellow with increasing $\mathrm{BF}_{2} \mathrm{AVB}$ concentration. This originates from the aggregated state formed in the polymer matrix, which depends on the stacking form of the parallel (B-phase), antiparallel (G-phase), and amorphous states. The emissive species show a hierarchal change with increasing $\mathrm{BF}_{2} \mathrm{AVB}$ concentration. For high $\mathrm{BF}_{2} \mathrm{AVB}$ concentrations, crystals form by segregation from the polymer matrix. The thermal stability of the polymorph with G-phase emission is higher than that with B-phase emission, suggesting that the polymer matrix isolation method can visually reveal Ostwald's rule of stages. The concentration-dependent fluorescence spectral changes also provide insight into the molecular assembly and crystal formation of the dye molecules.

\section{Acknowledgement}

This work was supported by JSPS KAKENHI Grant Numbers JP26410009, JP26107002, and JP15H01081 in Scientific Research on Innovative Areas "Photosynergetics".

\section{References}

1. A. M. Breul, M. D. Hager, U. S. Schubert, Chem. Soc. Rev. 2013, 42, 5366.

2 S. W. Thomas, G. D. Joly, T. M. Swager, Chem. Rev. 2007, 107, 1339.

3 R. Katoh, S. Sinha, S. Murata, M. Tachiya, J. Photochem. 
Photobiol. A. 2001, 145, 23.

4 J. C. D. Verhagen, M. vanZandvoort, J. M. Vroom, L. B. A. Johansson, G. vanGinkel, J. Phys. Chem. B 1997, 101, 10568.

5 C. Spies, R. Gehrke, J. Phys. Chem. A 2002, 106, 5348.

6 Y. Amao, I. Okura, Bull. Chem. Soc. Jpn. 2002, 75, 389.

7 T. T. Vu, M. Dvorko, E. Y. Schmidt, J. F. Audibert, P. Retailleau, B. A. Trofimov, R. B. Pansu, G. Clavier, R. Meallet-Renault, J. Phys. Chem. C 2013, 117, 5373.

8 G. V. Zakharova, A. R. Kombaev, K. Chibisov, High Energ. Chem. 2004, 38, 180.

9 F. Ito, R. Ohta, Y. Yokota, K. Ueno, H. Misawa, T. Nagamura, Chem. Lett. 2010, 39, 1218.

10 S. Sreeja, S. Sreedhanya, N. Smijesh, R. Philip, C. I. Muneera, J. Mater. Chem. C 2013, 1, 3851.

11 M. J. Currie, J. K. Mapel, T. D. Heidel, S. Goffri, M. A. Baldo, Science 2008, 321, 226.

12 J. L. Banal, J. M. White, K. P. Ghiggino, W. W. H. Wong, Sci Rep 2014, 4.

13 G. Griffini, L. Brambilla, M. Levi, C. Castiglioni, M. Del Zoppo, S. Turri, RSC Adv. 2014, 4, 9893.

14 C. Haines, M. Chen, K. P. Ghiggino, Sol. Energy Mater. Sol. Cells 2012, 105, 287.

15 A. Shundo, Y. Okada, F. Ito, K. Tanaka, Macromolecules 2012, 45, 329.

16 F. Ito, T. Kakiuchi, T. Sakano, T. Nagamura, Phys. Chem. Chem. Phys. 2010, 12, 10923.

17 F. Ito, H. Sato, Y. Ugachi, N. Oka, S. Ito, H. Miyasaka, Photochem. Photobiol. Sci. 2015, 14, 1896.

18 F. Ito, Y. Ugachi, T. Sasaki, Chem. Lett. 2012, 41, 282.

19 F. Ito, Y. Kogasaka, K. Yamamoto, J. Phys. Chem. B 2013, 117, 3675 .

20 M. Halik, W. Wenseleers, C. Grasso, F. Stellacci, E. Zojer, S. Barlow, J. L. Bredas, J. W. Perry, S. R. Marder, Chem. Commun. 2003, 1490.

21 E. Cogne-Laage, J. F. Allemand, O. Ruel, J. B. Baudin, V. Croquette, M. Blanchard-Desce, L. Jullien, Chem. Eur. J. 2004, 10, 1445.

22 K. Ono, K. Yoshikawa, Y. Tsuji, H. Yamaguchi, R. Uozumi, M. Tomura, K. Taga, K. Saito, Tetrahedron 2007, 63, 9354.

23 G. Q. Zhang, J. W. Lu, M. Sabat, C. L. Fraser, J. Am. Chem. Soc. 2010, 132, 2160.

24 G. Q. Zhang, J. P. Singer, S. E. Kooi, R. E. Evans, E. L. Thomas, C. L. Fraser, J. Mater. Chem. 2011, 21, 8295.

25 J. Samonina-Kosicka, C. A. DeRosa, W. A. Morris, Z. Y. Fan, C. L. Fraser, Macromolecules 2014, 47, 3736.

26 A. Sakai, M. Tanaka, E. Ohta, Y. Yoshimoto, K. Mizuno, H. Ikeda, Tetrahedron Lett. 2012, 53, 4138.

27 A. Sakai, E. Ohta, Y. Yoshimoto, M. Tanaka, Y. Matsui, K. Mizuno, H. Ikeda, Chem. Eur. J. 2015, 21, 18128.

28 F. Ito, T. Sagawa, RSC Adv. 2013, 3, 19785.

29 T. Sagawa, F. Ito, A. Sakai, Y. Ogata, K. Tanaka, H. Ikeda, Photochem. Photobiol. Sci. 2016, 15, 420.

30 G. Zhang, J. Chen, S. J. Payne, S. E. Kooi, J. N. Demas, C. L. Fraser, J. Am. Chem. Soc. 2007, 129, 8942.

31 H. W. Mo, Y. Tsuchiya, Y. Geng, T. Sagawa, C. Kikuchi, H. Nakanotani, F. Ito, C. Adachi, Adv. Funct. Mater. 2016, 26, 6703.

32 A. G. Mirochnik, B. V. Bukvetskii, E. V. Fedorenko, V.
E. Karasev, Russ. Chem. Bull. 2004, 53, 291.

33 A. G. Mirochnik, E. V. Fedorenko, T. A. Kaidalova, E. B. Merkulov, V. G. Kulyavyi, K. N. Galkin, V. E. Karasev, J. Lumin. 2008, 128, 1799.

34 M. Kasha, H. R. Rawls, M. Ashraf El-Bayoumi, Pure Appl. Chem. 1965, 11, 371.

35 Y. Hsu, T. L. Penner, D. G. Whitten, J. Phys. Chem. 1992, 96, 2790.

36 F. Ito, Y. Suzuki, J. Fujimori, T. Sagawa, M. Hara, T. Seki, R. Yasukuni, M. L. de la Chapelle, Sci Rep 2016, 6, 22918.

37 F. Ito, J.-i. Fujimori, CrystEngComm 2014, 16, 9779. 


\section{Graphical Abstract}

$<$ Title $>$

Concentration-Dependent Fluorescence Color Tuning of the Difluoroboron Avobenzone Complex in Polymer Films

$<$ Authors' names $>$

Fuyuki Ito* and Chika Kikuchi

$<$ Summary $>$

We have investigated the concentration-dependent fluorescence color tuning of $\mathrm{BF}_{2} \mathrm{AVB}$ in polymer films. $\mathrm{BF}_{2} \mathrm{AVB}$ exhibits a fluorescence color change from purple-blue to orange via green. This originates from the aggregated state depending on the stacking structure of the parallel, antiparallel, and amorphous states.

$<$ Diagram $>$

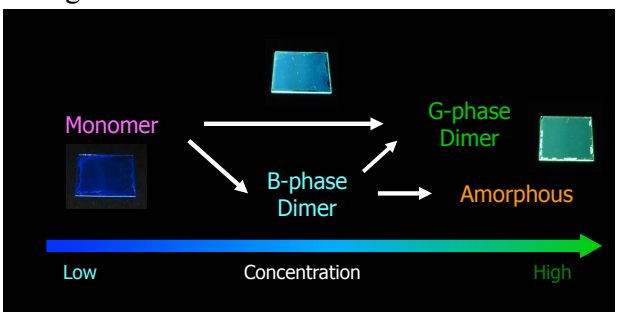

